\title{
Analysis of Mechanical Properties of Alternative MATERIAls FOR PROCESS FUSED DEPOSIT MODELING
}

\author{
Ahmet Cekic, Murco Obucina, Derzija Begic-Hajdarevic \& Miran Hebibovic
}
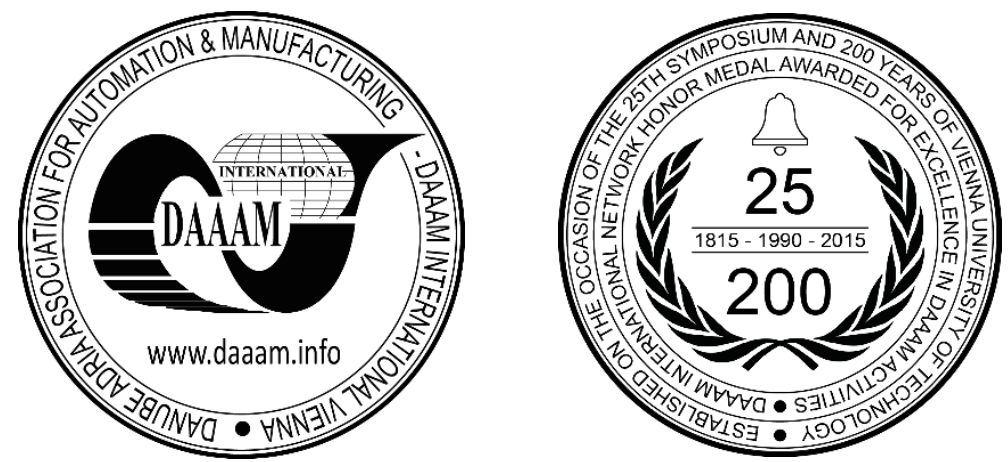

This Publication has to be referred as: Cekic, A[hmet]; Obucina, M[urco]; Begic-Hajdarevic, D[erzija] \& Hebibovic, M[iran] (2017). Analysis of Mechanical Properties of Alternative Materials for Process Fused Deposit Modeling, Proceedings of the 28th DAAAM International Symposium, pp.0253-0257, B. Katalinic (Ed.), Published by DAAAM International, ISBN 978-3-902734-11-2, ISSN 1726-9679, Vienna, Austria

DOI: $10.2507 / 28$ th.daaam.proceedings.034

\begin{abstract}
For the greater use of additive technologies in the industry, research is needed to discover new materials for the rapid creation of more functional products. New materials for additive production should overcome, with their properties, all the shortcomings of the most common polymer materials. On the other hand, it is preferable for the materials to be environmentally friendly and biodegradable. This paper presents experimental research results of the additive process parameters influence of Fused Deposit Modeling (FDM) process on product quality, using different materials. Two polymeric materials, PLA and Laywoo-D3 were used for the production of the samples. The obtained results show that for certain uses of the product and certain exploitation conditions it is possible to replace the environmentally inferior materials with the new materials obtained from the wood waste with a certain percentage of the adhesive. This has a positive impact on the environment, because wood is a natural and ecologically pure material $\left(\mathrm{CO}_{2}\right.$ neutral $)$.
\end{abstract}

Keywords: Additive Manufacturing; Fused deposit modeling; additive process parameters; mechanical properties of materials

\section{Introduction}

In order to meet the ever-demanding demands of the open world market and the earlier market entry of products as well as the faster return of invested funds, it is necessary, among other things, to reduce the development and production time to a minimum. An additional trend that is increasingly noticeable in certain segments of the market is the abandonment of mass production in favor of small-scale, and very often individual (personalized) production. To achieve these goals, Additive Manufacturing is increasingly being used today [1, 2]. The basic concept of Additive Technologies is that the products are made by adding and bonding the layer by layer. Additive Manufacturing processes do not require process flow planning, mold making, specific equipment for working with materials, transport between jobs, etc. It is important to note that to date on the world market, numerous of different Additive Manufacturing techniques (AM) have been implemented, and also devices with different technical characteristics are also available to users for all additive technologies. Namely, in addition to AM technologies, they differ in the way they generate the model, source of energy, starting material, etc. For each of these technologies, there are numerous devices produced by different manufacturers, and therefore different features (resolution, print speed, layer thickness, product dimensions, etc.). Although many 
different additive technologies have been implemented to date, they are not perfect and have certain limitations. The biggest drawback, at present, is the restriction on the use of certain materials [3 - 6]. One of the more frequent additive procedures is the Fused Deposition Modeling process - FDM, which is the subject of this paper. FDM is a process in which the wire-like material (polymer or composite) is melted and applied to the working surface by layer by layer in order to create a given model/product. According to the Wohlers Report, it is estimated that in the total market for additive technologies, FDM technology occupies more than $50 \%$ of the world market, [7]. In order to take advantage of this technology, it is necessary to analyze and define numerous influencing parameters. The most influential parameters of this process are:

- The temperature of the melted material for printing, as well as the temperature of the substrate and the chamber (quality and composition of the particular material matrix),

- Print speed and Layer thickness (device resolution),

- Filling density (from $0 \%$ to $100 \%$ ) and types (rectangular, triangular, corrugated, compact, 3D) model

- Number of external shell models,

- Orientation of the model (vertical, horizontal or combined),

- Support structure, etc.

Additionally, given the availability of numerous different types of materials for making the product by FDM, the choice of the appropriate material is a challenge, $[8,9]$. In addition to the model/product function, the selection of the appropriate material should take into account the following facts:

- Wire material diameter (type of device)

- Material color (model function)

- Class, type, condition and packaging materials, etc.

Materials for the FDM process can be polymeric (PLA, ABS, etc.) or composite, e.g. based on wood, metal or chalk powder or carbon fiber in combination with some of the polymers. The paper analyzes the possibilities of using alternative wood based material. Wood-based material (e.g. Laywoo-D3) is a mixture of recycled wood and a binding polymer. Wooden filaments from the PLA group contain an addition of wood fibers that give the finished products the appearance of wood. The percentage of these wooden accessories go up to $40 \%$. The material has similar thermal endurance as a pure PLA. Using this material will produce products that will look and smell of wood, and can be further processed the same as wood.

\section{Experimental research}

Previous research and optimization of the process parameters for achieving maximum product quality was done at the Center for Additive Technologies (CATeh) in Zagreb. After analysing the impact of all parameters on product quality and determining the optimal parameters for producing better products, the tubes were manufactured according to EN ISO 5272010 standard types, type 5. Tubes were manufactured with two different materials in order to test and compare their mechanical properties. The basic characteristics of the materials used for making the tubes are given in Table 1 . It is important to note that the material Laywoo-D3 is a composite material consisting of a combination of polymeric material (PLA) and recycled wood (the share of wood in the mixture $\sim 40 \%$ ). The material has a very low vitrification and good adhesion to the substrate. It is very muddy (like a filament), but it's much more flexible after printing. After printing, the products are soft, but after 24 hours they become stiffer. The reason for the lack of information about the Laywoo-D3 material is that it is relatively new on the market ie. the necessary research for the purpose of its greater application for the FDM procedure has not been completed, and the authors of this work plan for future research.

\begin{tabular}{|c|c|c|}
\hline Material & PLA & Laywoo-D3 \\
\hline Manufacturer & Flashforge & LAY Filaments \\
\hline Accuracy of production & $+/-0.02 \mathrm{~mm}$ & $+/-0.02 \mathrm{~mm}$ \\
\hline Diameter of the wire & $1,75 \mathrm{~mm}$ & $1,75 \mathrm{~mm}$ \\
\hline Melting temperature & $(160-190)^{\circ} \mathrm{C}$ & No information available \\
\hline Print temperature & $(180-230)^{\circ} \mathrm{C}$ & $(175-250)^{\circ} \mathrm{C}$ \\
\hline Tensile strength & $(37-60) \mathrm{Mpa}$ & No information available \\
\hline Elongation & $6 \%$ & No information available \\
\hline Modulus of elasticity & $4 \mathrm{Gpa}$ & No information available \\
\hline Density & $1,3 \mathrm{~g} / \mathrm{cm} 3$ & No information available \\
\hline
\end{tabular}

Table 1. The basic characteristics of the materials used for making the tubes 
The preparation of the tubes was performed on the Flashforge Finder and the process parameters are given in Table 2.

The following software packages were used to create the tube:

a) SolidWorks 2015 (used for three-dimensional modeling of the tubes/models in order to obtain 3D CAD models which will then be saved as .stl files),

b) Autodesk Netfabb 2017 (used to validate and repair the .stl file, and can also be used to prepare a print model),

c) FlashPrint (used to set the model, parameters, and cut of the models for the print process, ie. for its preparation, this program is the device that follows the device used).

\begin{tabular}{|c|c|c|}
\hline Material & PLA & Laywoo-D3 \\
\hline Thickness of the first layer & $0,27 \mathrm{~mm}$ & $0,27 \mathrm{~mm}$ \\
\hline Thickness of other layers & $0,18 \mathrm{~mm}$ & $0,18 \mathrm{~mm}$ \\
\hline Raft & YES & YES \\
\hline Wall & YES & NO \\
\hline Brim & YES & NO \\
\hline Fill (Slow type) & $100 \%$ & $100 \%$ \\
\hline Melting temperature & $220^{\circ} \mathrm{C}$ & $195^{\circ} \mathrm{C}$ \\
\hline Number of layers & 21 & 21 \\
\hline Print time & $85 \mathrm{~min}$ & $73 \mathrm{~min}$ \\
\hline Predicted material consumption & $11,9 \mathrm{~m}$ & $9,91 \mathrm{~m}$ \\
\hline
\end{tabular}

Table 2. Process parameters in the preparation of the test tubes for tensile testing

In addition to the aforementioned tube designer, testing of the tensile material was carried out in the laboratories of the Department of Mechanical Production Engineering at the Faculty of Mechanical Engineering in Sarajevo. The aim of testing the tensile material is to compare the obtained values for PLA and Laywoo-D3 materials. Material testing on tension was done in two ways:

a) The classic procedure at the Zwick Materialprufung Tensile Testing Machine 1435. The gauge range of the Tensile Testing Machine is from $0 \mathrm{kN}$ to $50 \mathrm{kN}$, and the displacement is $0.01 \mathrm{~mm}$.

b) Using the same testing machine, measuring tape and digital signal amplifier for drawing diagram force-unit elongation (F- $\varepsilon$ ) for Laywoo-D3 material. The measuring strips for the 6/120LY11 steel of the manufacturer HBM (Figure 1a) with characteristics: resistance $(120 \Omega \pm 0.35 \%)$, the active length of the measuring strip $(6 \mathrm{~mm})$, strip factor (k-factor $2.03 \pm 1 \%$ ) were used, thermal coefficient $\left(95 \cdot 10^{-6} \mathrm{~K}^{-1}\right)$. Digital Measuring Amplifier System - DMC 9012 A manufacturer by HBM (Figure 1b) with built-in amplifier DMV 55 for connection of electro-resistive measuring strips with characteristics: accuracy class $(0.05)$, measuring range $( \pm 3 \mathrm{mV} / \mathrm{V})$, maximum sampling rate $(9600 \mathrm{~Hz})$.

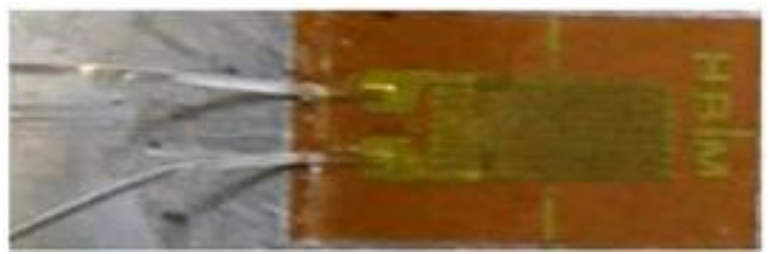

a) Electro-resistive measuring tape

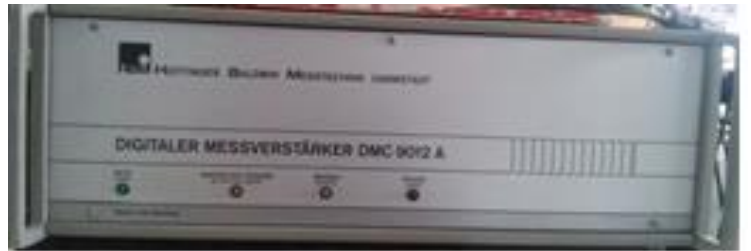

b) Digital measurement booster system

Fig. 1. Testing with measuring strips

After testing the tubes made of PLA and Laywoo-D3 materials, it can be determined the brittle fracture on all the samples on the basis of fracture surfaces for both materials that it was performed. Figure 2 shows Hook diagrams for PLA and Laywoo-D3 materials obtained by testing 10 tubes for comparison. The general conclusion is that all tubes achieved roughly the same measurement results, which is confirmed by the validity of the obtained F- $\Delta \mathrm{l}$ diagram, and therefore, in Figure 2, is given one diagram (average value) for both materials for transparency. During testing tubes of PLA material, maximum force (load) of $\mathrm{F}=1554 \mathrm{~N}$ was recorded, while the maximum force (load) $\mathrm{F}=377,3 \mathrm{~N}$ was recorded by testing the tubes produced from the Layoo-D3 material. Based on the diagram (Figure 2), we can conclude that Laywoo-D3 is a ductile material, but significantly lower tensile strength. Based on the maximum measured force values, the tensile strength for PLA is $\sigma_{\mathrm{PLA}}=38,86 \mathrm{MPa}$, and for Laywoo-D3 it is $\sigma_{\text {Laywoo-D3 }}=9,55 \mathrm{MPa}$. In addition to the above, the PLA has a lower contraction and elongation in yield on the Laywoo-D3 material. The contraction for PLA material on average is $\mathrm{A}_{\mathrm{PLA}}=4,71 \%$, and elongation $\delta_{\mathrm{PLA}}=3,66 \%$. For the Laywoo-D3 contraction, $\mathrm{A}_{\mathrm{Laywoo}-\mathrm{D} 3}=5,86 \%$, and elongation $\delta_{\text {Laywoo-D3 }}=4,93 \%$. 


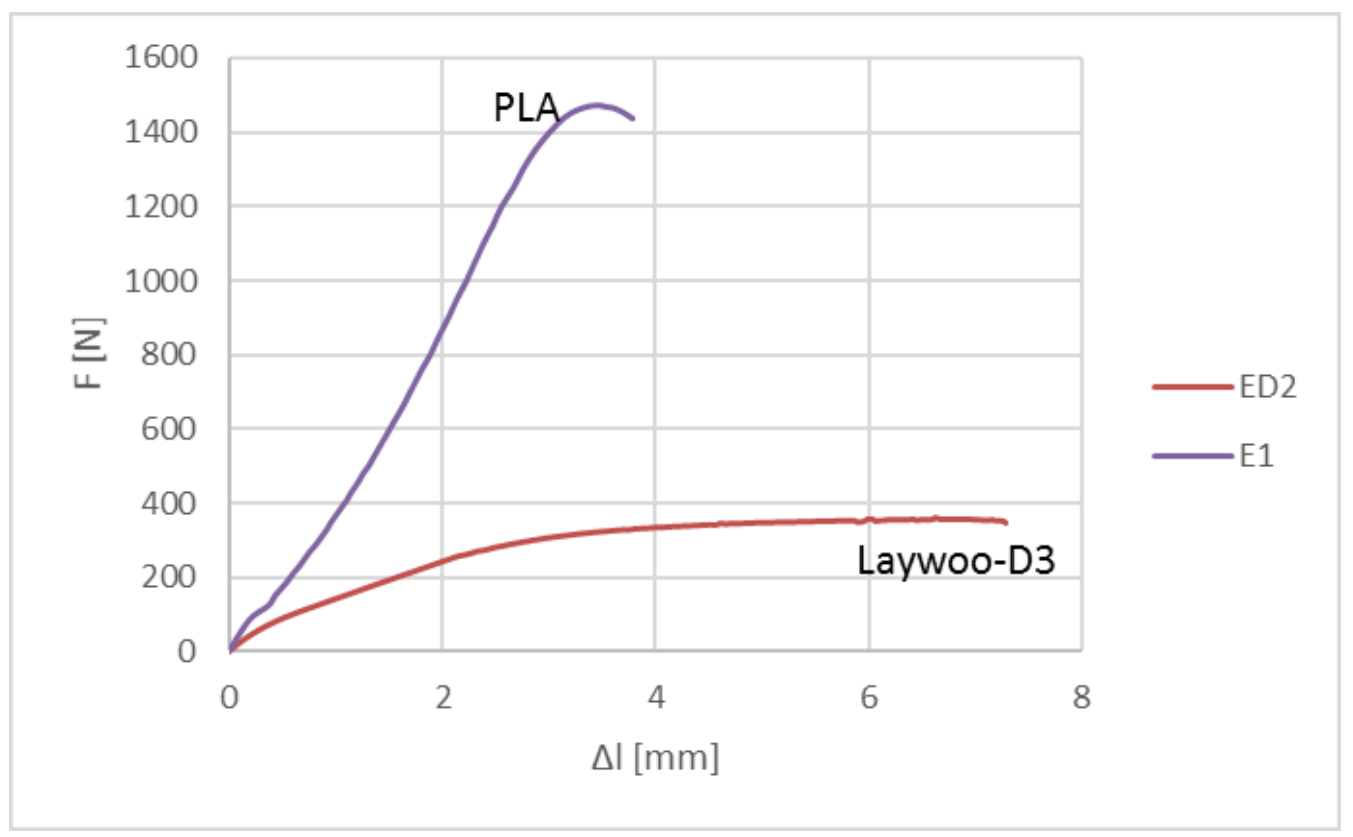

Fig. 2. Display of Hook Diagrams for PLA and Laywoo-D3 Material

Since it has been found that the Laywoo-D3 material is of a lower strength class, a measurement of the measured values and the use of measuring strip will be performed. Prior to the start of the measurement, the surface of the tubes was prepared for measuring the tape. In our case, two measuring strips were used (active and complementary) (Figure 3), where they used the Vilson semi-conductor for their connection. When connecting to the semi-conductor, it is essential that one contact from the active measuring strip is connected directly to the amplifier system. The second contact binds to one contact of the compensation measuring strip, so that these two contacts connect with one conductor to the measuring amplifier. The second contact, also from the compensation strip, is coupled to the measuring amplifier system via the conductor. Therefore, in the measuring reinforcement system there are three guides, one of which is common for two bands, and the other two go separately from each strip. In addition, the reinforcement system binds to ground.
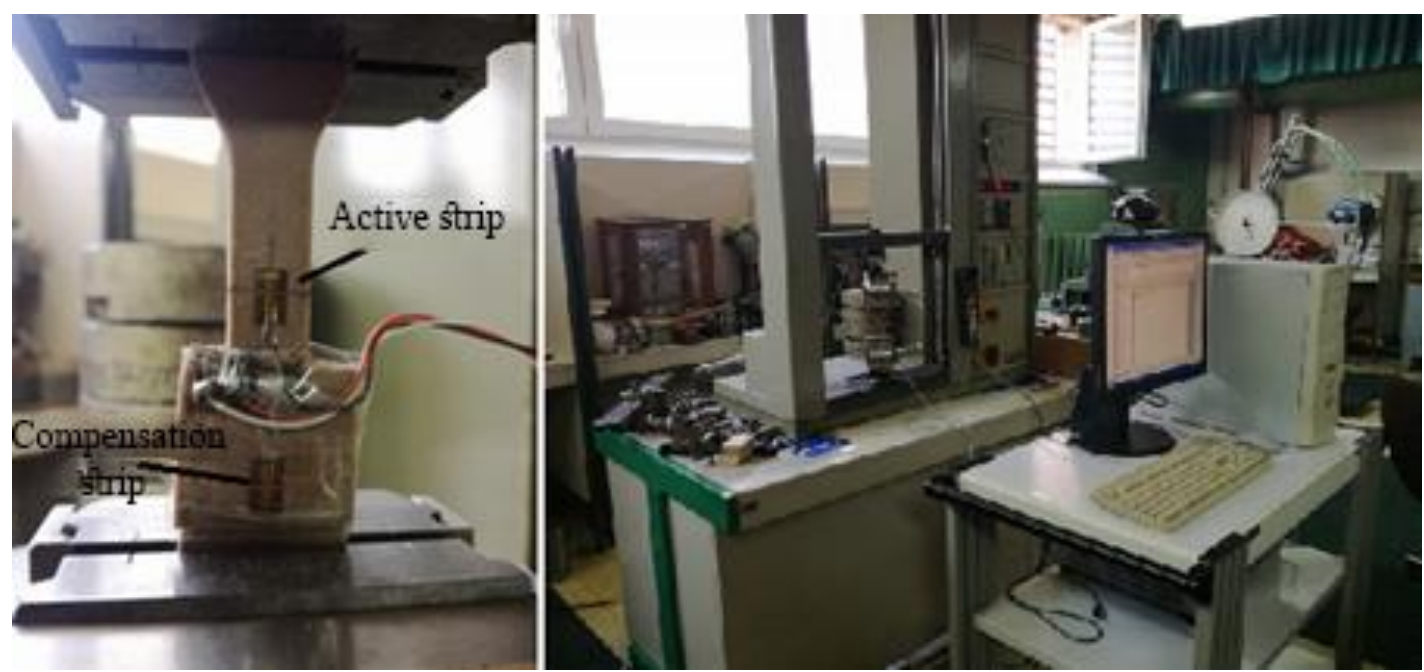

Fig. 3. Measuring equipment with the measuring strips

During the test with the measuring strips, due to their sensitivity, care should be taken to ensure that they do not get tangled. Testing of the material was made up to the $260 \mathrm{~N}$ load. During measurement, unit elongation monitoring was performed, which was changed in the unit of time. The unit elongation values were recorded on the basis of the displayed load on the tensile testing machine. Measurement of unit elongation for load values from $0 \mathrm{~N}$ to $260 \mathrm{~N}$ was performed. After the measurement has been performed, in order to compare the results obtained by this method with the previously applied method, all elongation values are divided by the initial length of the measuring part of the tube, i.e. $\mathrm{L}_{0}=30 \mathrm{~mm}$, in order to obtain a unit elongation. In Figure 4, Hook Diagrams are shown, in order to compare the obtained data using the classical method and the use of measuring strips. On the basis of the obtained diagrams we can conclude that the measured values on the tensile testing machine are valid. 


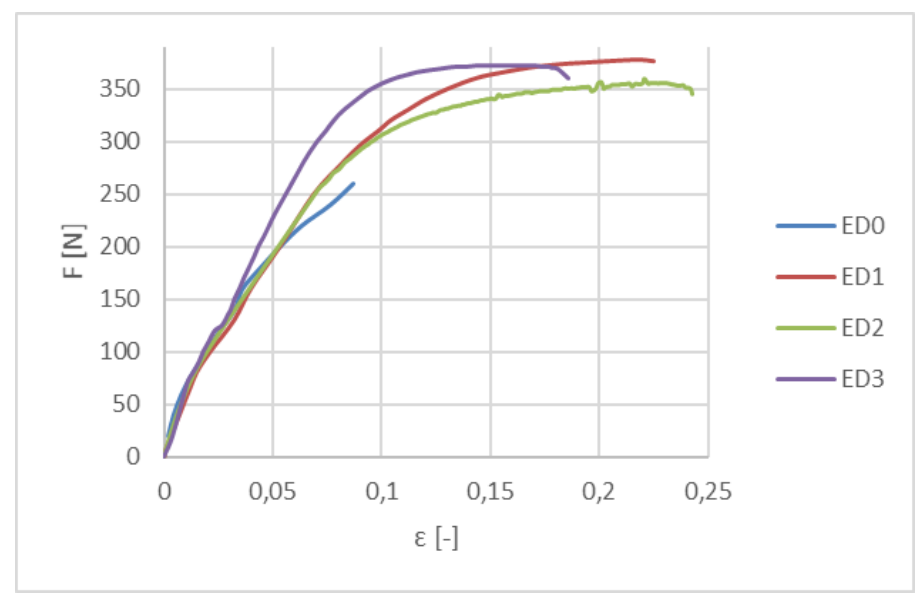

Fig. 4. Display and comparison of Hook diagrams for the Lajvoo-D3 material

\section{Conslusions}

Benefits of additive technologies, and therefore FDM (Fused Deposit Modeling) technology, are faster product development regardless of the complexity of the same. In this paper are presented the obtained experimental data on the research of the application of alternative materials with the additive process. The preceding testing, optimal parameters were defined for both materials: temperature and print speed, and resolution, occupancy, etc. parameters are defined for achieving the maximum quality of products on the given device. By testing the tensile material, it was found that the PLA material had about four times the tensile strength, but that the Laywoo-D3 was ductile. By further comparing the materials used, the Laywoo-D3 has an extremely good adhesion and no vitreousness occurs when printing, while an adequate substrate for better adhesion is required for the PLA material. Which material of the two listed will be used depends on the purpose of the product. It is recommended to use wood based materials, and if more solid products are required, the use of PLA materials is recommended.

For further research it is recommended to test the mechanical characteristics of (available and new) materials as well as other indicators of the quality of manufactured products with the added additive technology. It would also be desirable to make a test tube with the sameparameters, but on other similar FDM devices in order to compare the data obtained. The greatest emphasis on the development of this technology in the future is actually the development of new materials that can be used in the production of different products, which is a plan for further research by the authors of this paper.

\section{Acknowledgments}

The authors gratefully acknowledge the support of the Faculty of Mechanical Engineering University in Zagreb and Centre for Additive Technologies - CATeh Zagreb for this work.

\section{References}

[1] Valerga, A. P.; Batista, M.; Fernandez-Vidal, S. R.; Gomez-Parra, A. \& Barcena, M. (2016). Preliminary Study of the Influence of Manufacturing Parameters in Fused Deposition Modeling, Proceedings of the 26th DAAAM International Symposium, ISBN 978-3-902734-07-5, ISSN 1726-9679B. Katalinic, B. (Ed.), pp.1004-1008, Published by DAAAM International, Vienna, DOI: 10.2507/26th.daaam.proceedings.141

[2] Cekic, A.; Rasovic, N.; Obad, M.; Kaljun, J.; Dolsak, B. \& Begic-Hajdarevic, D. (2016). Production of optimized layered products using intelligent support, Proceedings of the 26th DAAAM International Symposium, ISBN 9783-902734-07-5, ISSN 1726-9679, Katalinic, B. (Ed.), pp. 0271-0279, Published by DAAAM International, Vienna, City, DOI:10.2507/26th.daaam.proceedings.037

[3] Mohamed, O.; Masood, S. \& Bhowmik, J. (2015). Optimization of fused deposition modeling process parameters: a review of current research and future prospects, Advances in Manufacturing

[4] Godec, D. \& Šercer, M. Aditivna proizvodnja, ISBN 978-953-7738-26-6, Zagreb, 2015.

[5] Kalani, K. H. \& Richard, H. 3D printing For Dummies A Wiley Brand, New Jersey 2014.

[6] Boschetto, A. \& Bottini, L. (2015) Triangular mesh offset aiming to enhance Fused Deposition Modeling accuracy, International Journal of Advanced Manufacturing Technology, 80 (99-111).

[7] https://wohlersassociates.com

[8] Salam, N. K.; Syed, H. M. \& Omar, A. M. An investigation on impact resistance of FDM processed Nylon-12 parts using response surface methodology, Australia 2016.

[9] Cupar, A.; Pogacar, V. \& Stjepanovic, Z. (2015). Shape Verification of Fused Deposition Modelling 3D Prints, International Journal of Information and Computer Science, 4. pp 1-8. 